\title{
Research on Extracurricular Sports Training in Universities from the Perspective of Sunshine Sports in China
}

\author{
Wenjie Zhu \\ P.E.Institute of Xuchang University, Xuchang, 461000, China
}

Keywords: Extracurricular sports training, Sunshine sports, University physical education

\begin{abstract}
The healthy physique of college students is an important cornerstone of national development. In order to improve the physical qualities of college students, the Chinese government has launched a concept of sunshine sports. However, from the implementation perspective of sunshine sports, there are many problems in it, such as lack of concept of extracurricular sports training, lack of platforms of extracurricular sports training and lack of facilities of extracurricular sports training. This paper makes a thorough analysis of the above problems and puts forward some countermeasures to provide some references for the development of sunshine sports in China.
\end{abstract}

\section{Introduction}

College Students' physical and mental health is the embodiment of the vitality of a nation and the symbol of social civilization and progress. College age is also a critical period for a person's physical and mental health and physical and mental development. The physical fitness of college students is not only related to individual health, but also to the health level of the whole nation. However, due to the impact of examination oriented education and the lag of physical education, the physique of college students is not satisfactory. This has become the bottleneck problem of the school physical education in our country. The introduction of sunshine sports is a tool to solve this problem. Sunshine sports are to enhance students' physical quality, improve the current situation of adolescent physical decline as the main purpose, through the physical exercise and the basic means to improve the quality of the people and to carry out the ultimate goal of school sports activities. The development of sunshine sports can attract the attention of the society to the improvement of teenagers' physique, and it can urge schools and related educational departments to pay attention to sports. Sunshine sports can train students to form the habit of physical exercise, improve their enthusiasm to participate in physical exercise, thus forming the awareness of lifelong physical education. Sunshine Sports enriches the current form of school physical education, and helps to improve the effect of physical education in school. Sunshine sports training helps the full development talents. Many colleges and universities have carried out vigorous Sunshine sports in the sports class, with remarkable results. However, under the class, sunshine sports cannot be effectively implemented. The condition of College Students' physical health decline has not been effectively curbed. How to effectively promote the development of sunshine sports in Colleges and universities and improve the health level of college students is a realistic problem to be solved urgently.

\section{Problems of Extracurricular Sports Training from the Perspective of Sunshine Sports}

Lack of Concept of Extracurricular Sports Training. For a long time, the focus and focus of college physical education has been classroom teaching. Classroom teaching is the protagonist, after-school sports is a supporting role, after-school sports is an extension and supplement of classroom teaching. This is the basic understanding of the university sports work and the basic orientation of after class sports. It cannot be denied that classroom teaching, as an important way of 
imparting and popularizing sports technology, has an irreplaceable function, and it also adapts to the development of the whole school physical education in our country at this stage. But if sport is the same as other subjects, it is only a course, and that is a mistake in itself. Because the mission of sports is to enhance physical and mental health. It is not the classroom teaching, but the physical and mental health of college students, that is the fundamental criterion for judging the merits of University sports. In recent years, the student's physique has been declining, and the school sports work has been repeatedly criticized, which fully illustrates this point. And to enhance the health of college students and ensure the physical and mental health of college students, classroom teaching is far from enough, and the physical quality of young students continues to decline, which proves it from one side. According to the university sports development model in some developed social sports countries in the west, the focus of the work is not in the classroom teaching, but in the spare time sports. With the continuous improvement of the socialization of sports in China and the gradual improvement of the reform of physical education curriculum, more students will have good sports quality. From the perspective of technology, technology acquisition needs of university classroom teaching of college students now should be a relative weakening trend. Therefore, from the perspective of development, college physical education should be different from primary and secondary school physical education, it should set up the curriculum concept, should be adhering to the complete teaching plan, the focus of the work of the sports gradually transferred from the classroom to extra-curricular, extracurricular sports focus, upgrading the status of extracurricular sports in the university.

Lack of Platforms of Extracurricular Sports Training. Although college students participate in after-school physical exercise can be carried out in an individual way, but the perfect organization will help to promote college students after school physical exercise. Sports competition is a popular form of sports participation among college students. In the sports consciousness weak, through the organization of competitions can cultivate students' effective participation in sports consciousness and interest, so as to make the extracurricular sports extensive long-term development and improving the quality of it. One of the most important reasons for the success of after-school sports in the world is that after school sports competitions are rich and colorful. Many universities have dozens of after-school sports competitions. This is a very successful experience for us to learn from. At present, our after-school sports competition is also a small number, incomplete, and mainly competitive sports and classroom teaching projects. Many events with large participation and interesting interest, as well as a great lack of national traditional sports which students love to see. Some students are reluctant to take part in after-school exercises because of lack of exercise partners. The extracurricular sports participation of college students is greatly influenced by environment and groups. Student sports clubs can effectively promote college students' extracurricular sports participation, improve their interest in physical exercise and improve their physical exercise behavior. In recent years, college sports organizations, represented by clubs, have developed in spite of some development. However, compared with the needs of college students after their spare time physical training, the development is still very slow. Many students' sports organizations are still in the stage of nominal, and to some extent, it also affects college students' Extracurricular Sports participation. The lack of after-school sports training is an important reason why the concept of sunshine sports cannot be put into practice in colleges and universities.

Lack of Facilities of Extracurricular Sports Training. Field equipment is a material guarantee for college students to take part in after-school sports activities. After the enrollment expansion of colleges and universities, serious shortage of facilities and equipment has become one of the major problems that restrict students' after class physical training. College students are not allowed to take part in after-school exercises because of restrictions from venues and equipment. Only half of the university sports venues and facilities can meet the needs of teaching, extracurricular activities and sports training. Less than half of the college sports equipment is equipped to meet the needs of teaching, extracurricular activities and sports training. Most of the students think that the spare time sports facilities are insufficient. Further investigation revealed that the reasons for inadequate venues are not entirely due to inadequate construction, but the result of a combination of factors, there are three main factors. The first reason is the "peak accumulation" effect of exercise. Most students 
concentrate on afternoon exercises or evening exercises. The second reason is the phenomenon of exercise congestion. Students mainly concentrated in basketball, football, billiards, badminton and other popular, fashionable items. Finally, the living area is separated from the campus or the distance is too far, and there are no corresponding sports facilities in the living area. The existing sports venues, regardless of school size, there are fewer, the average per capita inadequate site burden on students weighing, indoor venues, swimming pool, a serious shortage of the situation. The phenomenon that university sports venues are occupied and misappropriated is also a factor that cannot be ignored. Many colleges and universities have become victims of the market economy. Some of the planning and misappropriation of the relevant provisions of the failure to limit the amount of compensation or lack of compensation, the direct impact of the existing stadium effective area. The unreasonable use of the existing stadiums and gymnasiums by the management departments of sports venues in colleges and universities is also the cause of the excessive burden on the stadiums.

\section{Countermeasures of Extracurricular Sports Training from the Perspective of Sunshine Sports}

Cultivate Fitness Consciousness. We should strengthen the understanding of the necessity and urgency of developing physical education in Colleges and universities, such as management departments, institutions of higher learning and physical education teachers. The sports teaching goal of our system actively solve the traditional simple to improve students' physical quality as the goal, set up to improve the students' physical quality, cultural quality, lifelong learning ability and other elements of a new sports teaching target system. By deepening the understanding of the sunshine sports education by the management departments of higher institutions, we should strengthen the resources input and guarantee mechanism for the development of physical education in Colleges and universities. Strengthen the system construction of physical education in Colleges and universities, and ensure the operation and effectiveness of sports education programs. Sports and health are closely related. Sport is the guard of life. Life lies in movement. To change the phenomenon of College Students' sports consciousness is weak, in addition to strengthen physical exercise guidance, let the personal experience to the role of sports on the body, but also actively carry out life education, find strong support for the role of sports in life. Through a large number of vivid, intuitive and understandable cases, students fully understand the significance of physical exercise to life. The effectiveness of education, people are gradually rid of one sidedness, say goodbye to abnormal development. Unfortunately, the vast majority of colleges and universities in China now think that sports are simply physical activities. The teacher or creation of sports theory class, the students either echo what the books say, of no interest to teach more and more tired. As a life support role in life, physical activity, and only must be fully conscious of it on the value of life in the students' exercise behavior, it may be willing. Therefore, only through the breakthrough of life education, stimulate their willingness to exercise, it is possible to find the source and lasting power for college students to practice extracurricular physical exercise.

Develop Sports Organizations. Associations and clubs are good media. Students participate in extracurricular sports activities in certain organizations, which can stimulate students' sense of honor and participation in the organization, and improve their interest in physical exercise. Schools should actively organize clubs and clubs for sports events. Physical education teachers as the guiding teachers' daily training on community guidance. It is an important way for students to form the consciousness of lifelong physical size. Schools are the basic stage for students to develop their sports behavior habits and sports concepts, so as to provide more opportunities for students to contact various sports programs. The school sports associations form to guide students in sports activities, can effectively control the school extracurricular activities to intervene too much, promotes the student to the sports flexible choice, and there is someone for training plan, avoid sports injuries and the exercise intensity is not appropriate to bring physical discomfort. In the course of teaching innovation, should be in badminton, table tennis, football, swimming and other traditional competitive sports based on the program, to further enrich the aerobics, folk sports and other educational and teaching content. Sunshine sports can enhance students' interest in physical 
education and enrich their choice of space. In extracurricular teaching innovation, we should actively establish sports associations and develop sports clubs in Colleges and universities. We can hold sports cultural festivals, carry out lectures, competitions and other forms of sports knowledge. We set up a multi-level and wide field Sunshine Sports extracurricular teaching activities, so as to promote the realization of the goal of sunshine sports education.

Improve Facilities Construction. By extending the free time of sports venues for students, lowering the charging threshold, increasing the rate of students' borrowing of sports facilities and facilities, the time and space for students to participate in sports activities after school hours are guaranteed. Through modern communication networks and tools, timely release of physical education, physical fitness, and other related knowledge and information. A multi-purpose, old field new use. Strengthen the organization and management of sports work, to some of the usual difficulties in the management of venues, may be appropriate to carry out new sports projects paid service activities and club organization and management, in order to improve the use efficiency of existing venues. We will strengthen ties with public sports stadiums, sports schools, communities and factories, so as to increase the utilization rate of stadiums and gymnasiums in the whole society, so as to increase the activity space and time effectively. The number of swimming pools in universities is seriously insufficient, and the per capita area of indoor stadiums is less than that of social sports venues. Qualified schools can set up sports courses online learning and communication platform through the sports work department website to consolidate the learning effect of college sports classes, and meet the diversified needs of College Students' sports learning methods. Teachers should respect the dominant position of students in their studies, especially the differences between their physical and physical abilities. For students with poor physical quality, teachers should give priority to encouragement and cannot be impatient for success. At present, solutions of College Stadiums except for the lack of new venues, avoid embezzlement and misappropriation, more important is the colleges and universities should fully and reasonably use the existing stadiums, and strive to improve the efficiency in the use of existing facilities.

\section{Conclusion}

Sunshine sports is an important component of the content of quality education. In the future development process, China's universities also need to implement the concept of sunshine sports into the university after school to further cultivate the awareness of fitness, develop the sports organizations and improve facilities construction. Only in this way can China culture more and more talents with good bodies.

\section{References}

[1] Zhao Chenglei. Analys is on the Choice of Extracurricular Sports under the Plight of Sunny SportsMovement for College Students [J]. Journal of Beijing Sport University, 2012, 35(1): 87-91+110.

[2] Xiong Ling. Discussion on Relationship between the Sunshine Sports Program and the Physical Activities after Class [J]. Bulletin of Sport Science \& Technology, 2012(2): 64-65.

[3] Chang Yuanyuan. The Current Situation and Countermeasures of School Extracurricular Sports Activities under the Background of “Sunshine Sports” [J]. Sport Science and Technology, 2016, 37(5): 116-117.

[4] Wang Bo, Zhou Xuerong, Li Huimeng. Confusion and Reflection on College Physical Education Curriculum from the Perspective of "Sunshine Sports” [J]. Journal of Beijing Sport University, 2014, 37(5): 112-117. 